BULLETIN (New Series) OF THE

AMERICAN MATHEMATICAL SOCIETY

Volume 37, Number 1, Pages 1-2

S 0273-0979(99)00852-6

Article electronically published on December 21, 1999

\title{
INTRODUCTORY COMMENTS
}

\author{
DONALD G. SAARI
}

"The extraordinary development of mathematics in the last century is quite unparalleled in the long history of this most ancient of sciences. Not only have those branches of mathematics which were taken over from the [nineteenth] century steadily grown but entirely new ones have sprung up in almost bewildering profusion, and many of these have promptly assumed proportions of vast extent."

For illustrations it is not necessary to reach to the beginning of the century when topology, or functional analysis, or K-theory, or many other topics had yet to be discussed; just consider the last thirty years with the new research areas which have come into existence and with the parade of major results. These rapid changes and stunning advances have, most surely, transformed the latter part of the twentieth century into one of the most exciting times to be a mathematician. What underscores the continuing vitality of our field is that by changing the above bracketed "nineteenth" to "eighteenth" we recover the opening paragraph of Pierpont's [2] 1904 review of nineteenth century mathematics!

The year 2000 provides an opportunity, perhaps an excuse, to review where we are and how we got here. An excellent resource can be old issues of the Bulletin, where changes in emphasis reflect the development of American mathematics. By thumbing through brittle, aged pages, one can trace the emergence of mathematical standards, starting with an admission that "the notion of rigor is relative and depends on what we are willing to assume either tacitly or implicitly" [2]. The earlier dependency of American mathematics on foreign studies is captured by comments (e.g., [1]) that "American students of mathematics, who intend to devote their lives to the subject, have generally in the past deemed it wise to spend more or less time at a European university, ... [and] this migration will continue." Travel leads to cultural differences: "True it is that an American who studies at Oxford must wear academic dress at the proper times and seasons, and must forego the dangerous habit of carrying weapons such as javelins, while at Cambridge, he will not be allowed to play marbles on the steps of the Senate House. ... In Italy, however, the statutes are planned for one type of student wishing one thing, and when the student presents himself who wants something else the process of adjustment is difficult and jarring."

An appreciation of the maturing of mathematics comes from reading the struggles with what now are elementary properties of groups, the mysteries of "infinities", or observations that " $\mathrm{t}]$ he first years of this century have seen an interest in vectors and related subjects, such as has never before been observed. ... [T] he champions of the various systems come forward to press upon us the advantages of their particular system and especially the disadvantages of all others. Felix Klein is at the head of a commission to investigate the relative merits of different methods, ..." [3]. 
To suggest how mathematics has changed, this issue reprints selected Bulletin articles from the early part of the twentieth century and extracts from book reviews from the first two-thirds of the century. The articles were selected to indicate how far we have progressed by emphasizing where we were. The issue starts with Fiske's description of the founding days of the AMS and the Bulletin and continues with Pierpont's review of nineteenth-century advances in mathematics. It includes assessments by van Vleck and G. D. Birkhoff's Presidential Address. Poincaré's 1904 appraisal of the challenges faced by twentieth-century mathematical physics describes, in part, the then hot topic of relativity, ending with the challenge that perhaps "we shall have to construct an entirely new mechanics," a challenge met the following year by A. Einstein. Indeed, the fourth article is Einstein's 1934 Gibbs Lecture about the equivalence of mass and energy. One of the controversies of this century is represented by L. E. J. Brouwer's discussion of intuitionism and formalism.

Rather than trying the impossible of capturing the evolution of twentieth-century mathematics, we offer only a small taste. It is hoped that these articles and reviews will encourage readers to enter the dusty, far reaches of a mathematics library to thumb through old Bulletin issues. I promise you a delightful afternoon.

\section{REFERENCES}

[1] Collidge, J. L., The opportunities for mathematical study in Italy, Bulletin 11 (1904), 9-17.

[2] Pierpont, J., The history of mathematics in the nineteenth century, Bulletin 11 (1904), 136-159.

[3] Wilson, E. B., Vector analysis, Bulletin 11 (1904), 17-21.

Department of Mathematics, Northwestern University, Evanston, IL 60208-2730

E-mail address: bams@math.nwu.edu 